\title{
NATIONAL VARIATIONS OF THE INFORMATION SOCIETY: EVIDENCE FROM THE GREEK CASE
}

\author{
Dimitris Boucas \\ London School of Economics and Political Science, UK
}

\begin{abstract}
Identifying an empirical gap in the examination and analysis of the information society (IS) in semi-peripheral and middle income countries, the paper seeks to address the evolving characteristics and forms of the "Greek case" of the IS, stressing the dialectic between European policy and the national socio-cultural, political and economic idiosyncrasies, the weaknesses encountered, and the role of the state in articulating the global and the national through rhetoric and policy. Drawing on historical sociology, I propose that the historically developed relationship between the state, and the national economy and society will interact with global IS processes, creating differentiated national IS outcomes. The emphasis of the study is on the period 1998-2006, which includes the first comprehensive IS strategy in Greece and provides the opportunity to assess preliminary results of the policies adopted.
\end{abstract}

Keywords: Information society, IT policy, state, implementation politics

\section{Introduction}

The concept of the "information society" (IS) denotes a new techno-socioeconomic paradigm around information and communication technologies (ICTs), involving a set of significant economic and social transformations and bearing implications for governance and potential for development and quality of life [6, 33, 57]. ${ }^{1}$

This chapter examines how trust can emerge and be sustained in the context of mobile transactions, through an ethnographic study of M-PESA, a mobile banking system deployed in Kibera-one of Africa's largest slums.

\footnotetext{
${ }^{1}$ As the term "information society" has been deployed to capture different kinds and scales of social (economic, political etc.) transformation, a definition will be inadequate. Our working definition of IS: a form of economic and societal organisation at various levels, which emerges when the diffusion of ICTs interacts with pre-existing social, economic, cultural, political arrangements, which involves new patterns of living and working, and where, in addition, information and knowledge are considered central assets for competitive advantage, profit, growth, and employment.
}

Please use the following format when citing this chapter:

Boucas, D., 2008, in IFIP International Federation for Information Processing, Volume 282; Social Dimensions of Information and Communication Technology Policy; Chrisanthi Avgerou, Matthew L. Smith, Peter van den Besselaar; (Boston: Springer), pp. 63-79. 
A central question in relevant debates has been whether the IS formation constitutes a radical break with previous societal arrangements. In this respect, some speak of the IS as a new type of society in a deterministic way [2, 3], while others prefer to identify continuities with industrial capitalist societies and place ICTs in context, trying to identify the profound transformations deriving from the articulation between new technologies and pre-existing economic, social, political, and cultural processes [1,33,47]. The former approaches imply some kind of homogenisation lens and anticipate a uniform IS, while the latter allude to variation and context-specific differentiations of the ICT paradigm. Contrary to previous research, recent agendas have placed emphasis on the interplay between society and technology in the IS outcomes. National variations are gradually becoming accepted and attributed to different national political and socio-cultural circumstances, as well as different institutional structures and traditions, which are seen to influence not only the outcome of IS policy, but also practice. Moreover, they are expected to reflect often conflicting ambitions and aspirations of different arrays of involved actors and users.

Indeed, "national cases" of the IS are beginning to become objects of study both in the European context [8, 22, 46] and beyond [7]. What seems to be missing, however, is an examination and analysis of the IS in semi-peripheral and middle-income countries. In this paper I examine the evolution of the IS policy in the Greek context, in conjunction with the evolution of similar policies at the EU level. In doing so, I limit my analysis to IS policies in Greece during the 1990s and up until 2006, a period which includes the introduction of the first comprehensive IS strategy as well as its reception and preliminary effects.

My argument is that the unfolding of any national IS is a contested process feeding on previous, historically rooted, social, economic, cultural, and political arrangements. Specifically, I propose that the historically formed state/society relation at the national level is expected to inflect global IS processes in quite idiosyncratic ways, leading to differentiated national IS trajectories and outcomes. My research question is: What are the IS policies implemented in Greece in the period under examination and how have they interacted with pre-existing national characteristics (as encompassed broadly in the state/society relation)?

The structure of the paper includes a brief background presentation of IS policies at the EU level and in Greece. Subsequently, it provides a concise picture of the current situation of Greek IS based on certain ICT diffusion indicators. These provide a preliminary picture of "lagging behind". In order to explain why this is the case, the paper uses a state/society approach based on tools from historical sociology. A brief presentation of the state/society approach is followed by an account of the historical evolution of the state/economy/civil society relation in Greece. The characteristics of this relation are then used to identify continuities and explain constraints of the IS in Greece at present, as they emerge from a set of in-depth interviews with key IS actors. Conclusions are drawn, including implications for future studies of national case of IS. 


\section{IS policy at the EU level}

An IS vision has been, since the 1990s, communicated at the EU level, with the intention of promoting diffusion of ICTs at various geographical scales, including national, sub-national, regional, supra-national, EU-wide, and even beyond. The 1993 European Commission White Paper on growth, competitiveness, and employment was the first influential policy document communicating this vision, revealing the importance attached by policy makers to the opportunities and challenges for European competitiveness, growth and employment, particularly in skilled jobs and new services [13].

Subsequently, the well-known Bangemann Report was produced for the March 1994 meeting of the European Commission in Corfu. The report set out the following priorities: a) promoting the use of information technologies; b) providing basic services at a European level; c) creating an appropriate regulatory environment; d) developing training in new technologies; and e) improving technological and industrial performance [14]. These proposals were followed by the action plan "Europe towards the information society", designed by the Commission in July 1994 [15].

The EU Lisbon summit in March 2000 declared the goal of making Europe the most competitive knowledge-based economy ${ }^{2}$ while maintaining social cohesion and cultural diversity [10]. Moreover, a new open method of inter-state coordination was adopted for the translation of European goals into national policies, through European guidelines, best practices, references indicators, but also room for national diversity through targets and measures fitting each nation's case [44]. The new method was applied to IS policies in the "eEurope 2002: An Information Society for All" initiative, launched in December 1999. This outlined ten priority areas for joint action by the Commission, the member states, the industry and the citizens [16]. The subsequent "eEurope 2005" action plan set out to stimulate Internet services, applications and content, to improve the underlying infrastructure (promotion of broadband, awareness of security matters) and to promote ICT skills and ICT-based opportunities. Recently, the i2010 EU plan aims at promoting a borderless information space and internal market for electronic communication, ensuring inclusion, accessibility, and quality of life.

The EU IS policy, particularly the eEurope initiatives, has had an impact on the formulation of strategic national programmes. Recently there have been certain degrees of convergence with regard to the tone and content of the IS policies adopted. Nonetheless, as IS policy-making in the national context still rests with the authority and power of the member states, similar frameworks might lead to different translations, according to the different state/society traditions in different member states of the EU [41]. As a result, many possible forms of the European

\footnotetext{
${ }^{2}$ A knowledge-based economy has been defined as one where knowledge is being created, diffused, and deployed in accelerated ways through ICTs; where increasingly sophisticated products codify and manage knowledge; and where there is a perception of knowledge as a strategic asset for individuals, firms, and nations [45].
} 
IS are expected, depending on technological developments, interaction with users, as well as national policies and the general societal culture. The role of the state is particularly important in articulating international policy imperatives with national specificities.

\section{IS policy in Greece}

The first policy document regarding the IS in Greece was the 1995 White Paper "The Greek Strategy for an Information Society: A Tool for Employment, Development and Quality of Life", which served as a means of setting the IS agenda in the Greek context. It echoed the discourse of opportunity associated with the new technology and was mainly concerned with the inadequate national infrastructure, which limited electronic transactions and access to new products and services both for firms and for households. Most of its actions have been funded by the $2^{\text {nd }}$ Community Support Framework (CSF): the development of a national infrastructure linking universities, technological institutes and public research institutes, the promotion of an e-commerce environment for business, or actions to raise public awareness of e-commerce [9, 25].

While all operational programmes of the $2^{\text {nd }}$ CSF included funding for the IS, the operational programme Kleisthenis (1994-2000) was the key IS initiative. Its central aim was the modernisation of public administration through an integrated approach to IT, including development of infrastructures, applications and training in the design and implementation of each separate project. In parallel, the digitisation of the public telecomms operator (OTE) network, the development of certain fibre optic rings, and the creation of the national network for research and technology (EDET) were important telecommunications initiatives. During this period a small number of IT firms of significant size developed, the IT sector was consolidated and entered the Athens stock market in the end of the 1990s.

Like in all other EU countries, the first major step towards the implementation of the IS was the liberalisation of telecommunications sector, which until the late 1980s was based on a state monopoly in telephony and telecommunication services. In the wake of the early EU IS documents, a series of laws carried forward the liberalisation of telecommunications, starting from value-added services and mobile telephony services (Law 1892/90 and 2075/92) and culminating with Law 2860/2000; after 31 December 2000 all restrictions including those on the provision of voice telephony and the network infrastructure were removed and full competition was officially established, under the supervision of an independent regulatory authority, the National Telecommunications and Post Commission (EETT) [38].

In 1999, a more strategic and comprehensive second White Paper titled "Greece in the Information Society: Strategy and Actions" was prepared by ten policy experts based on international experience and feedback from the Ministries regarding the actions and steps that had been taken vis-à-vis the IS. Its rhetoric emphasised the potential of ICTs for competitiveness and better public services, 
present in the early EU documents, together with the requirement of building human skills to take advantage of these opportunities. The imperative of universal access and the prevention of new types of social exclusion, reminiscent of similar concerns in EU documents, were also highlighted [26].

Following from the White Paper, through the eEurope initiative of 1999 and the Feira Summit of June 2000, the Greek government proposed a systematic "Operational Programme for the Information Society" (OPIS), linking it to funds within the structure of the $3^{\text {rd }} \mathrm{CSF}$. This was an innovative horizontal programme, involving a number of government departments, and aiming to implement the essential features of the 1999 White Paper.

The OPIS objectives over the period 2000-2006, with the corresponding shares of national and EU funding, were: a) to address issues of infrastructure and training in education and promote Greek cultural heritage $(17 \%)$; b) to provide better services to the citizen and improve the quality of life through the deployment of ICTs in public administration, health and welfare, transport and the environment $(37 \%)$; c) to promote the economy through actions to increase competitiveness and employment and to help SMEs enter the digital era (24\%); d) to enhance telecoms liberalisation, development of broadband and local networks and facilitate access for remote areas and disadvantaged groups (19\%). The OPIS also included a technical support for the above actions $(3 \%)[9,39]$.

According to Law 2860/2000 several bodies were set up to manage and implement the OPIS: a) The Management Authority, operating under the Special Secretariat for the Information Society was established within the Ministry of National Economy, which deals with the design of action lines for the OPIS, the follow-up and control of their implementation, as well as supervision of financial, legal, and logistical aspects; b) The Monitoring Committee comprising representatives of ministries, public organisations, economic and social partners and having a supervisory and advisory role; c) The IS S.A., a public not-for-profit organisation which is charged with the administration of public calls for tender for projects seeking funding under the OPIS, while also providing assistance and advice to government and other public and private institutions in the implementation of the OPIS; d) The IS Observatory, aiming at transferring expertise and best practice relevant with IS issues, as well as providing training tools and supervising benchmarking studies [5].

\section{Current picture of the IS in Greece}

In 2000, when the OPIS had just begun, Greece was significantly behind the EU-15 average in ICT infrastructure and use, with the exception of fixed and mobile telephones. Table 1 shows an increase in PC and Internet usage for individuals and PC and Internet possession for households between 2001 and 2003, but this increase cannot be characterised as a take-off; on the contrary, falling rates were observed between 2003 and 2004 [12]. 


\begin{tabular}{|l|c|c|c|}
\hline \multicolumn{1}{|c|}{ Indicator } & $\mathbf{2 0 0 1}$ & $\mathbf{2 0 0 3}$ & $\mathbf{2 0 0 4}$ \\
\hline \% population over 15 using PC & 20.8 & 27.1 & 25.9 \\
\hline \% population over 15 using Internet & 10.6 & 19.9 & 19.7 \\
\hline \% population over 15 with email address & 6.5 & 12.4 & 12.5 \\
\hline $\begin{array}{l}\text { \% population over 15 using Internet to } \\
\text { interact with public authorities }\end{array}$ & $3.5(2002)$ & 6.1 & 7.2 \\
\hline \% households having PC & 23.3 & 30.5 & 29.9 \\
\hline \% households having Internet access & $12.4(2002)$ & 15.2 & 17.1 \\
\hline \%households with broadband connection & - & 1 & 1 \\
\hline \% population having mobile phone & 49.5 & 64.7 & 69.4 \\
\hline
\end{tabular}

Table 1: Evolution of basic IS indicators in Greece.

At the enterprise level, in $200392 \%$ of firms with 11-250 employees possessed PCs (94\% in the EU), $82 \%$ were connected to the Internet ( $83 \%$ in the EU), while $48 \%$ had also a website (52\% in the EU). These tendencies were reinforced through the "eBusiness" action of the OPIS, resulting in an $87 \%$ Internet connection in 2004 (90\% for the EU-15). Very small enterprises (up to 10 employees) lagged significantly behind the EU average in 2003. The "Go-Online" programme for small enterprises, which subsidises initial purchases of ICT and also provides training, is expected to have an important contribution in this context (according to a recent survey, 60\% of small entrepreneurs were of the opinion that the programme could sufficiently address their needs) [11, 40].

Although the support of investment towards broadband infrastructures has been one of the fundamental priorities of the OPIS, in 2004 only $1 \%$ of households and only $21 \%$ of enterprises were connected with broadband, percentages that were by far the lowest in the EU-15 and among the lowest even in the EU-25 [18, 40].

In the public sector, diffusion and deployment of ICTs has been limited in almost all areas, which also explains the low use of Internet-mediated interaction with public authorities (7.2\% of the population over 15 in 2004). Exceptions have been certain parts of the TAXIS Net project (addressing fiscal procedures), as well as the area of education and training, with the development of the advanced Greek Research and Education Network (GRNET) [17].

In 2006, Greece presented among the lowest percentages in EU-25 (including the new EU accession countries) in the following categories: Internet usage at least once a week by individuals (23\% compared to $47 \%$ for EU-25), Internet access by households ( $23 \%$ compared to $52 \%$ for EU-25), and PC usage among the population $(33 \%$ in 2005$)$. Internet access among enterprises was about $94 \%$ (93\% for EU-25), but broadband access was 58\% (74\% for EU-25), while broadband Internet access by households was $4 \%$, the lowest percentage in the EU-27 [19]. 


\section{The Greek IS in historical perspective}

Notwithstanding certain "success stories" Greece is still significantly behind not only in terms of ICT diffusion, but also with respect to the overall economic, social, cultural, and institutional aspects of the IS project. The few attempts to assess the Greek IS situation have stressed that policy formation has been accompanied by inadequate or unsuccessful policy implementation [5]. I would rather treat implementation impediments as symptomatic of broader characteristics of the national context in question that have been developed over time. These (social, economic, political, cultural) dimensions have been consolidated into structural elements and have informed social practices. The fact that Greece has historically shown receptiveness to the idea of modernisation at a first level, but has found difficulties in the actual absorption and deepening of new ways of living and working [56], further legitimates a historical approach.

\subsection{State/society: Embedded autonomy and state capacity}

Being interested in capitalist diversity and national variations, I adopt a state/society historical theoretical approach. The value of a state/society approach is related to alerting the researcher to the historical unfolding of a national economy/society relation (and inescapably the role and evolution of the specific national state in this unfolding). As such, it prepares the ground for an adequate comprehension of the outcomes of what has been operating as the IS project at the international level by considering pre-existing historically formed (at the national level) economic arrangements, social relations, cultural characteristics, institutional traditions, together with the role of the particular state in socioeconomic development. By doing so, however, it does not rule out the (global) structural context in which such national variations are placed, but highlights the anticipation that the impact of IS global processes will depend on the nature of the society and the state (seen through the state/society relation) under examination.

Comparative political economy and political sociology have been preoccupied with state/society debates at least since the 1970s, when demands to "bring the state back in" were responding to "society-centred" approaches which were seen as attributing to the state a secondary position in terms of analytical importance $[43,48]$. The ensuing state-centric theories were stressing the notion of "state autonomy", which initially communicated the idea of independent state bureaucratic and policy-making activity, was subsequently coupled with the idea of embeddedness of state mechanisms into the wider society, resulting in the notion of "embedded autonomy", which denotes that states "are embedded in a concrete set of social ties which binds the state to society and provides institutionalised channels for the continual negotiation and renegotiation of goals and policies" [20, p. 12]. Based on comparative research, Evans [20] argues that the ways in which states are coupled with their societies vary significantly and this 
relates to the role of the state in the economy, which can be either developmental or detrimental to economic development (or a mixture of both).

The concept of embedded autonomy sought to overcome the division between state autonomy and embeddedness into the social structural context. Evans claims that the more state bureaucracies approach Weber's ideal type (i.e., based on meritocratic recruitment, secure careers and rewards, and independence from external interferences) the more they can contribute to economic development [21]. However, autonomy from external interference (from business, church, military, etc.) is not enough and it is only through embeddedness into society (close societal links) that such policies can have successful outcomes [27].

The degree to which the state enjoys embedded autonomy also affects the capacity of the state, which involves resource endowment, quality of leadership and political institutions, as well as tradition of governance, national culture and previous political decisions [49, p. 2]. It presupposes capable public bureaucracies, together with competent leadership and the ability of the state to organise social contracts and promote goals in democratic ways. This in turn calls for the participation of societal forces and the promotion of an active civil society and eventually a healthy and organic relationship between state and society [29].

The analytical notions of embedded autonomy and capacity of the state are taken to express the embeddedness of state mechanisms in wider societal arrangements and their institutional capabilities (ample or limited) to promote social projects. These two (not mutually exclusive) concepts are expected to capture the IS development process at the national level as a social process.

In the following section, I adopt a historical perspective claiming that the specific state/economy/civil society relation, as has been historically shaped in Greece, can serve as explanatory device of current developments in the Greek IS.

\subsection{State, economic development, and civil society in Greece}

The dominant reading of Greek history places Greece in the capitalist semiperiphery, as well as the late-late development paradigm (i.e., economies where industrialisation only happened after 1929), which is associated with an increased role of the state or state-controlled institutions [36].

The gradual integration of the Greek economy into the world market and the process of urbanisation in the late $19^{\text {th }}$ century gave an important role to the state for building infrastructure, regulating prices and exports, etc. The articulation of agriculture with industry took place in ineffective ways and resulted in a quite limited domestic market. Increasing urbanisation led to rising unemployment for large segments of population drawn in urban centres and created pressures for those segments of urban population to be absorbed in public bureaucracies [51].

As a result, the public sector size augmented and public administration became fragmented and inefficient, while state support and regulation became gradually linked with clientelism which was used as a vehicle for absorbing social tensions. On the other hand, since state structures were already in place before 
industrialisation took off in the 1930s, a tendency emerged for the private sector to operate under the protective mechanisms of the state (e.g., seeking increased subsidies, enjoying protection through high tariffs or other kinds of favourable treatment), rather than building its own independent capabilities [32]. Further, these practices were applied in asymmetrical ways between industries or within an industry, with certain economic groups enjoying privileged access to public resources. The above processes gave the state anti-developmental structural features, which had an impact on the industrialisation and development prospects [37, 54]; in contrast with Western Europe in the 1950s and 1960s, light industry and consumer goods dominated in Greece.

Further, the late industrialisation of Greece, as well as the role of the state in economic development, have also affected the character of civil society. ${ }^{3}$ Firstly, insufficient industrialization prevented the development of traditional industrial unionism, with much lower rates of unionisation than Western Europe. The union movement in Greece has been characterised by considerable fragmentation, which has made collective action difficult, while it has facilitated the development of links between individual unions and the government and other political entities. In contrast to the corporatist arrangements in Western Europe, Greece has demonstrated asymmetric corporatist arrangements, with state-dependent trade unions and at the same time weakness of the state vis-à-vis business interests, something which has limited effective collective decision-making and the negotiation of social pacts [31]. Other parts of civil society have either been more or less dependent on the state (e.g., social movements like the feminist movement, the Church etc.), or have been powerful but reactive to any reform that would affect their privileges (e.g., the professional associations of lawyers, doctors, or engineers). Clientelism has also had a significant impact on civil society, potentially drawing citizens towards individual political participation and thus impeding the formation of horizontal associations to promote common goals and interests $[37,50]$.

After the dictatorship (1967-1974) and into the post-1974 era, the Greek governments focused on economic development and accession to the EU. After 1981, when the newly elected PASOK socialist government sought to accommodate its voters by creating new posts, clientelism took a new form as it moved from personalised relationships to a practice operating through parties. Populism and short-term practices led to an exacerbation of economic indices and of the condition of public enterprises. On the other hand, trade unions became more dependent on the state due to their politically-appointed leaderships, while PASOK also exerted great influence on professional associations and civil society associations.

In socio-cultural terms, the prevalence of clientelism, together with weak trade unions and social movements, as well as the polarisation engendered by the Civil

\footnotetext{
${ }^{3}$ Following Sotiropoulos, we take civil society to be "a wide-ranging set of social interaction and collective action taking place in the public space available between the individual household, on the one hand, and the state apparatus, on the other" $[52$, p. 10].
} 
War (1944-49), the reliance on the family and disassociation from broader social collectivities, have contributed to social heterogeneity and have prevented the development of a universalistic and collective culture [42].

\subsection{Analysing the current picture of the Greek IS}

The dominant characteristics of Greek state, politics, economy, and society emerging from the historical evolution have been seen as features to some extent common in the South European context. Since the 1970s, south European countries have been witnessing processes of democratisation, Europeanisation, and modernisation and have approximated Western and Northern Europe in terms of partisan politics and economic change. Nonetheless, the Southern European state and its patterns of public policy outputs have continued to exhibit legacies that impede substantial change (in certain sectors more than in others) [24].

During the 1990s the ambitious socio-economic "modernisation" project of Prime Minister Simitis (1996-2004) set out to secure the position of Greece at the core of EU both in economic (including incorporation in the core of the Eurozone) and in political terms [23]. The comprehensive IS strategy, as demonstrated through the 1999 White Paper and the OPIS, has to be seen in this context.

In what follows I try to present a more detailed picture of the problems encountered in the implementation of the IS strategy based on data obtained through a set of elite interviews carried out between 2005 and 2006 with key state actors involved in the OPIS, as well as with representatives from the IT sector. These interviews were unstructured and in-depth based on a topic guide of general questions. They were also complemented by my personal observations of the IS evolution over the period 1998-2006, including important meetings, conferences, and debates in which we have participated. The presentation attempts to link the evidence with the particular components of the state/society relationship shaped historically as outlined in section 5.2.

\subsubsection{Policy processes}

The public policy process in Greece has been often seen as hierarchical, with complex relations between ministers and personal advisors operating across ministries, weak support from civil service, and the absence of think tanks and policy communities that would provide technocratic legitimation [30]; as a result, political initiatives suffer from antagonisms and competing interests within government agencies. Moreover, such antagonisms are exacerbated through highly conflictual relations between the political parties, based on opposing social identities and patronage systems [23].

Regarding the OPIS, there has been from the beginning a significant problem of antagonism between ministries as to the allocation of responsibilities. As a senior member of the team designing the OPIS remembers: "the whole programme run the risk of being abandoned, as the three ministers involved...all wanted to break the OPIS and receive separate chunks of pertinent CSF funds 
directly for their ministries... Ultimately the deadlock was resolved at the level of the Prime Minister with two ministries taking the responsibility, namely the ministry of National Economy and the ministry of Interiors. This duality, which was necessary for the programme to be approved, has taken its toll in terms of delays, coordination difficulties, and antagonisms and enmities with regard to who 'carries the flag' of the information society in Greece". Rivalries were constant throughout and the absence of a continuous IS vision at the prime ministerial level perpetuated them.

\subsubsection{Bureaucracy, public procurement, and the IT sector}

The historical evolution presented in 5.2 has ascribed to bureaucracy certain characteristics that often describe the "Southern European model of bureaucracy" and that have been persistent in Greece in the beginning of the $21^{\text {st }}$ century. Firstly, political clientelism at the top level, meaning the political party-mediated appointments at the top levels of bureaucracy, as well as promotions and transfers to high civil service. Secondly, political clientelism at the low levels, i.e., selective recruitment at entry-levels jobs in public administration. Thirdly, lack of an institutionalised administrative elite with considerable political and social stature and a corresponding lack of Weberian bureaucratic culture based on rational/legal expertise. Fourthly, the uneven character of the public sector, with unbalanced distribution of personnel and resources [53]. These characteristics have participated crucially in the evolutionary course of IS in Greece.

On the one hand, there has been observed an overall incapacity of the state to carry out, monitor, and implement certain IT projects. As a central figure of the Management Authority remarked, "The most obvious reason for this has been the lack of project management personnel both capable and aware of the contours of the Greek reality that could navigate through a labyrinth of problems and procedures". On the other hand, as a senior member of a large IT firm put it: "Implementation has also been impeded by the complexity of the legal, administrative, and institutional framework for IT projects". This seems to have characterised public procurement mechanisms as a whole, reflecting the fragmentation of public administration that has been formed historically. Indeed, members of the Special Secretariat have reported that the perpetuation of obsolete structures (e.g. different departments for telephony, IT and Internet, and different departments dealing with procurement for those technologies) has blocked or delayed significantly projects, particularly those of an innovative nature. It is important to stress that the first projects did not start until about 2 years after the launch of the OPIS.

In addition, incorporation of a project in the daily administrative routines have been particularly difficult as lack of understanding and motivation on the part of employees. All in all, the public sector is inadequate as provider of digital products and advanced applications, as well as consumer of digital products and services. Its rationalisation and digitisation is seen as pivotal in ICT-related social transformation [4]. 
The historical characteristics of Greek capitalism and its relationship with the state have been reflected in the current state/IT sector relations in Greece. The incomplete industrialisation and the resulting small market has been reflected in an IT sector of limited scope, with very few SMEs and large enterprises and a vast majority of small and micro firms. This has differentiated Greece from other national cases where large ICT firms have acted as leading edge technological innovators (e.g., Nokia in Finland). Further, the relationships of dependence of firms on the state observed in the industrial era have been reproduced in phenomena whereby the IT firms, although private, have relied extensively on state promises for funding that either have not been materialised, or, have not been accompanied by appropriate monitoring of industrial performance [55]. As an advisor to the former Special Secretary remarked, "the private sector in Greece is mainly retail, with very low value-added, waiting mainly for the public sector to implement projects. This tendency is dominant in the IT sector...the market does not create its own dynamic, but waits from the state to generate projects". This has been confirmed by other state actors, as well as IT representatives in a relevant meeting in February 2006 to which the author was granted access.

Moreover, clientelism and micro-corruption have been frequently involved in IS project allocation and have been accompanied by a defiance of rules and codes of conduct during implementation. Lack of IT expertise has often resulted in public administration succumbing to pressures from the IT sector to purchase products and adopt solutions in accordance with what specific IT firms have to offer. The relevant committees involved have either obstructed allocation of projects or have made bribery commonplace, while the IT firms in Greece have been used to the logic of bribing every committee for allocating or evaluating a project.

More specifically, there has been observed the phenomenon of a small number of hegemonic firms able to appropriate the majority of projects, with obvious implications for fair competition. As a former Management Authority member reports: "The practice of such firms was either to bribe the pertinent committees in order to get the project, or to establish such connections and relationships with ministry employees and cadres, which gave them early access to information as to what the specifications of the project were and as a result comparative advantage in the preparation of their proposals for the project in question. In many cases, these dominant firms were in the position to create the specifications themselves". These phenomena led another interviewee to remark: "Characteristics of the industrial era are replicated in exactly the same way today. We have state dependent enterprises and the logic of appropriation of resources, funds etc by the small segment of "the selected"'.

Overall, the absence of formal procedures guiding IT actions have perpetuated unhealthy relations of dependence and distrust between the state and the IT firms, which in turn have prevented the development of patterns and relations of mutual accountability, trust, and smooth cooperation between the private and the public sector. The state/IT sector relation has reflected the overall state/economy 
relations, which have been historically characterised by over-regulation and strict legal frameworks on the one hand, while suffering on the other from an unhealthy relationship of mutual dependence which involves corruption and patronage in the allocation of favours and contracts [28].

\subsubsection{Civil society}

On the other hand, the historically unbalanced state/civil society relation and the general lack of collective spirit is reflected in the limited part of civil society in the evolution of the IS project in Greece. Social networks and local communities that could help advance the IS (as has happened in Finland, for instance) by increasing awareness, have either been absent or characterised by inertia. Indeed, the wider social forces and civil society groups do not seem to have comprehended the dimensions of IS developments or have simply shown a logic of appropriation. As a senior EDET member argued: "The OPIS articulated policies that were out of touch with the Greek context and were not acceptable by the Greek society. Conflicts of interests and local communities did not help the promotion of ICTs, either because actors were acting out of their own interest and only regarding their own interest or because local communities were not in a position to understand".

In parallel, there have been examples of civil society acting through a culture of short-termism and quick profit-making. In addition, the issue of inadequate investment culture has frequently come up in our interviews. For instance, it has been suggested that IT sector representatives have repeatedly reacted against the prospect of spending funds on education programmes (something that would indirectly boost demand) and have instead demanded channelling them towards direct purchases of IT equipment. Generalising, it can be argued that the culture of short-termism has been a drawback in the realisation on a social level of multiplier economic and social effects resulting from the promotion of the IS.

\subsubsection{IS, state capacity, and embedded autonomy in Greece}

During the period 1998-2006, the Greek state has demonstrated limited capacity regarding the promotion of the IS; the design of a comprehensive OPIS has been confronted by implementation problems. Specifically, there has been inadequate leadership in understanding and communicating the IS vision at the societal level and in organising it as a central socio-economic project in the political agenda; a lack of appropriate political institutions and of a political culture that would serve such a broad and all-encompassing project; the presence of an anti-Weberian state bureaucracy, devoid of the rational-legal expertise and the administrative culture needed to contribute to socio-economic development; a lack of participation of broader social forces towards the IS development goals.

To put it in slightly different terms, in the context of IS, the Greek state/society coupling has demonstrated limited "embedded autonomy". On the one hand implementation of policy has been enmeshed in various personal and institutional interests, clientelistic relations, and micro-corruption (inadequate autonomy of the 
state from society). On the other hand the IS project has been designed top-down without social dialogue and with subsequent limited mobilisation of civil society, while the links between state and entrepreneurs at the local level have been weak (inadequate embeddedness of state into society).

\section{Conclusions}

Despite following closely the EU rhetoric and policy, the unfolding of the Greek IS has come up against significant delays and impediments. At the state level, obsolete institutional arrangements, inadequate coordination and implementation mechanisms, and the lack of Weberian bureaucratic culture, have delayed project implementation. At the industry level, the IT sector in Greece has been characterised by a vast majority of small and very small enterprises, has not been competitive enough, and has been implicated in complex relationships with other productive entities and the public sector. At the societal level, lack of awareness, ignorance, and technophobia vis-à-vis the new technologies have been observed, due to inadequate education/training, inadequate communication of the national vision, and the absence of driving forces like those of civil society. Apart from the sphere of private consumption (e.g. through mobile telephony) the IS project has not been meaningful to large segments of the Greek population.

I have analysed this picture by resorting to the history of the Greek social formation and by adopting a state/society approach. I have argued that incomplete industrialisation, a complex relationship between the state, the economy and politics, a fragmented, over-bureaucratic and inefficient public administration, inactive civil society, collective spirit and social heterogeneity, as well as the operation of clientelism, have all contributed to the contemporary picture of the Greek IS. Moreover, "state capacity" and "embedded autonomy" can be useful concepts in understanding the current standing of the Greek IS and the associated implementation problems.

The goal of this paper has been twofold: firstly, to provide a critical account of the IS in a specific national context and its particularities; secondly, to draw on this case in order to lead to theoretical propositions as to the impact of the particular state/society configuration and the role of the state on IS in a national context. The methodological implication of this research is that historical studies of societies can be informative of contemporary IS developments. The Greek case shows that national variations should be taken seriously in discussions of the IS, as the adoption and implementation of IS policies is a contested process that comes up against historical societal legacies. These legacies are expected to contribute to the trajectory and eventual physiognomy of any national IS (as further research in the Greek and other cases in future might demonstrate). 


\section{References}

[1] Avgerou, C. (2002). Information systems and global diversity. Oxford: Oxford University Press.

[2] Baudrillard, J. (1988). Selected writings. Cambridge, Polity.

[3] Bell, D. (1976). The coming of post-industrial society: A venture in social forecasting. Harmondsworth, Penguin.

[4] Caloghirou, Y. (2003). Implementing information society development strategy in Greece. Seminar on Information Society as Tool for Regional Development, Salerno.

[5] Caloghirou and Constantelou (2006). Addressing the complexity challenge: Some reflections on the non-linear route of putting policy into practice. European Communications Policy Research Conference (EuroCPR), Seville.

[6] Castells, M. (1996). The rise of the network society. Oxford: Blackwell.

[7] Castells, M. Ed. (2004). The network society: A cross-cultural perspective. Cheltenham, UK: Edward Elgar.

[8] Castells, M. \& P. Himanen (2002). The information society and the welfare state: The Finnish model. Oxford: Oxford University Press.

[9] Constantelou, N. (2001). In search of a vision: Information society policies in peripheral and middle-income countries. Athens: National Technical University.

[10] Council of the European Union (2000). Conclusions of the Lisbon European Council. SN 100/00. 23-4 March 2000.

[11] EDET (2004). 2003 Market study for e-commerce. Resource document. E-Business Forum. www.ebusinessforum.gr (in Greek). Accessed October 2005.

[12] EDET (2005). 2004 National survey for new technologies and the information society. E-Business Forum. www.ebusinessforum.gr (in Greek). Accessed October 2005.

[13] European Commission (1993). Growth, competitiveness, employment: The challenges and ways forward into the $21^{\text {st }}$ Century. A white paper. Luxemburg: Office for Official Publications of the European Communities.

[14] European Commission (1994a). Europe and the global information society: Recommendations to the European Council. Brussels: European Council.

[15] European Commission (1994b). Europe's way to the information society: An Action Plan. COM(94) 347. Brussels: European Commission.

[16] European Commission (2000). eEurope 2002: An information society for all: Action Plan prepared for Feira European Council. Brussels: European Commission.

[17] Eurostat (2003). Statistics on the information society in Europe. Luxembourg: Office for Official Publications of the European Communities.

[18] Eurostat (2005). Internet usage by individuals and enterprises. Luxembourg: Office for Official Publications of the European Communities.

[19] Eurostat (2007). Statistics on the information society in Europe. Luxembourg: Office for Official Publications of the European Communities.

[20] Evans, P. (1995). Embedded autonomy: States and industrial transformation. Princeton, NJ: Princeton University Press.

[21] Evans, P. \& J. E. Rauch (1999). Bureaucracy and growth: A cross-national analysis of the effects of "Weberian" state structures on economic growth. American Sociological Review, 64(5), 748-765.

[22] Falch, M. \& A. Henten (2000). Digital Denmark: From information society to network society. Telecommunications Policy, 24(5), 377-394.

[23] Featherstone, K. (2005). Introduction: 'Modernisation' and the structural constraints of Greek politics. West European Politics, 28(2), 223-241. 
[24] Gunther, R., Diamandouros, N.P., \& Sotiropoulos, D. (Eds) (2006). Democracy and the state in the new southern Europe. New York: Oxford University Press.

[25] Hellenic Republic (1995). Greek strategy for the Information Society: A tool for employment, development and quality of life. Athens: Hellenic Republic.

[26] Hellenic Republic (1999). Greece in the information society: Strategy and actions. Athens: Hellenic Republic.

[27] Hobson, J. M. (1998). The historical sociology of the state and the state of historical sociology in International Relations. Review of International Political Economy, 5(2), 284-320.

[28] Kazakos, P. (2001). Between state and market. Athens: Patakis (in Greek).

[29] Kotzias, N. (2004). The active democratic state. Athens: Kastaniotis (in Greek).

[30] Ladi, S. (2005). The role of experts in the reform process in Greece. West European Politics, 28(2), 279-296.

[31] Lavdas, K. (2005). Interest groups in disjointed corporatism: social dialogue in Greece and European 'competitive corporatism'. West European Politics, 28(2), 297316.

[32] Lyberaki, A. \& E. Tsakalotos (2002). Reforming the economy without society. New Political Economy, 7(1), 93-114.

[33] Mansell, R. E. \& Steinmueller, E. (2000). Mobilizing the information society: Strategies for growth and opportunity. New York, N.Y: Oxford University Press.

[34] May, C. (Ed.) (2003). Key thinkers for the information society. London: Routledge.

[35] Miles, I. (1996). The information society: Competing perspectives on the social and economic implications of ICTs. In W.Dutton (Ed.), Information and communication technologies: Visions and realities. New York: Oxford University Press.

[36] Mouzelis, N. (1986). Politics in the semi-periphery. London: Macmillan.

[37] Mouzelis, N. (1995). Modernity, late development and civil society. In J.Hall (Ed.), Civil Society: Theory, history, comparison. Cambridge: Polity.

[38] OECD (2001). Regulatory reform in Greece. Paris: OECD.

[39] OPIS (2000). Operational programme for the information society. Ministry of National Economy. www.infosociety.gr (in Greek). Accessed May 2005.

[40] OPIS (2004). Operational programme for the information society Performance Review 2003. www.infosociety.gr (in Greek). Accessed September 2005.

[41] Perrons, D. (2004). Globalisation and social change: People and places in a divided world. London: Routledge.

[42] Petmesidou, M. (1996). Social protection in Greece: A brief glimpse of a welfare state. Social Policy and Administration, 30(4), 324-347.

[43] Phillips, N. (2005). Special section: The state debate in political economy. New Political Economy, 10(3), 335-342.

[44] Rodrigues, M. J. (2002). Introduction: For a European strategy at the turn of the century. In M. J. Rodrigues (Ed.), The new knowledge economy in Europe (pp.1-27). Cheltenham: Edward Elgar.

[45] Rodrigues, M.J. (2003). European policies for a knowledge economy. Cheltenham: Edward Elgar.

[46] Sancho, D. (2002). European national platforms for the development of the information society. In J. Jordana (Ed.), Governing telecommunications and the information society in Europe. Cheltenham: Edward Elgar.

[47] Sassen, S. (2002). Towards a sociology of information technology. Current Sociology, 50(3), 365-388.

[48] Skocpol, T. (1985). Bringing the state back in: Strategies of analysis in current research. In P. Evans, D. Rueschemeyer and T. Skocpol (Eds), Bringing the state back in (pp. 3-37). Cambridge: Cambridge University Press. 
[49] Smith, D., Solinger, D, \& Topik, S. (Eds.) (1999). States and sovereignty in the global economy. New York: Routledge.

[50] Sotiropoulos, D. (1996). Civil society and the Greek state in the Third Hellenic Republic. In C. Lyrintzis, E. Nikolakopoulos and D. Sotiropoulos (Eds), Society and politics. Athens: Themelio. (in Greek).

[51] Sotiropoulos, D. (2003). Aspects of Babylonia: Interpretations of the post-war development of welfare state in Greece. In D. Venieris and C. Papatheodorou (Eds), Social policy in Greece: Challenges and perspectives. Athens: Ellinika Grammata (in Greek).

[52] Sotiropoulos, D. (2004). Formal weakness and informal strength: civil society in contemporary Greece. Discussion Paper 16. London: LSE Hellenic Observatory.

[53] Sotiropoulos, D. (2006). Old problems and new challenges: The enduring and changing functions of the southern European state bureaucracies. In R. Gunther, P. N. Diamandouros and D. Sotiropoulos (Eds), Democracy and the state in the new southern Europe (pp 197-234). New York: Oxford University Press.

[54] Tsoukalas, C. (1977). State, society, work. Athens: Themelio (in Greek).

[55] Voulgaris, Y. (2003). Greece and the information society: Particularities and strategic choices. Contemporary Issues (in Greek).

[56] Voulgaris, Y. \& Sotiropoulos, D. (2002). Information society, sociology and technology. Operational Programme for Information Society. www.ebusinessforum.gr/teams/teamsall/view/index.php?ctn=60\&language=en (in Greek). Accessed 15 December 2004.

[57] Webster, F. (2006). Theories of the information society. London: Routledge. 